\title{
DEVELOPMENT OF YOUTH VOLUNTEER PROGRAMS IN THE CONDITION OF THE COVID-19 PANDEMIC IN THE COMMUNITIES, NEIGHBORING TO THE AREA OF THE JOINT FORCED OPERATION IN THE EAST OF UKRAINE
}

\author{
Tetiana Liakh \\ Borys Grinchenko Kyiv University, Ukraine \\ Maryna Lekholetova \\ Borys Grinchenko, Kyiv University, Ukraine \\ Anastasiia Kotelevets \\ Borys Grinchenko Kyiv University, Ukraine \\ Tetiana Spirina \\ Borys Grinchenko Kyiv University, Ukraine \\ Olha Shved \\ Borys Grinchenko Kyiv University, Ukraine
}

\begin{abstract}
Volunteering is popular among young people in Ukraine. This is especially important for the communities, neighboring the area of the Joint Forces Operation in the East of Ukraine.

However, one of the current challenges for the volunteer program development has been quarantine restrictions due to the COVID-19 pandemic. The main goal of the article is to analyze the participation of young people in volunteer programs during the quarantine restrictions related to COVID-19, in the communities neighboring the area of the Joint Forces Operation in the East of Ukraine.

The authors of the study used the "rapid appraisal" technique. Thus, in May 2020, the authors interviewed 22 representatives of state and non-government organizations of Donetsk and Luhansk regions of Ukraine which implemented youth volunteer projects. The study revealed challenges caused by quarantine restrictive measures which have been grouped by authors into two groups: organizational and methodological. The answers of the respondents provided the basis to identify the positive outcomes caused by the change of the usual format of youth volunteer programs and its development: mastering of distant forms of communication by employees; development of qualitatively new ideas and introducing training programs for volunteers; increasing the ability to use the Internet to promote volunteer programs; practicing online volunteering.
\end{abstract}

Keywords: COVID-19, Joint Forces Operation in the East of Ukraine, volunteer activity, volunteer program, volunteer, youth. 


\section{Introduction}

It is the seventh year of fighting in the East of Ukraine, and the situation in the conflict-affected Luhansk and Donetsk oblasts negatively affect the lives of more than five million people. People in the affected areas face physical and mental health problems, such as shelling, the destruction of homes and civilian infrastructure, limited access to social services, and limited freedom of movement. There are also problems with a number of regulations that lead to humanitarian needs in a conflict situation. Finally, people face challenges in their ability to recover and rebuild, both in terms of social cohesion and the implementation of social development programs, using the capacity of local and national authorities.

Restrictions related to COVID-19 have exacerbated the difficulties and disadvantages faced by the conflict-affected population in eastern Ukraine, in particular through restrictions on freedom of movement and their impact on social and economic rights, and active participation in the volunteer movement.

In Ukraine, the active development of volunteering began with the adoption of independence in 1991. Since then, numerous public organizations and charitable foundations have been established, which have involved volunteers in the implementation of social projects, so they acted on a volunteer basis. But the greatest wave of volunteering among youth led to the emergence in 1993 of social services for youth. This all-Ukrainian network of public services was created as one of the mechanisms for the implementation of state youth policy (Declaration on General Principles of State Youth Policy in Ukraine, 1993). At that time, one social worker of this service had at least three areas of social work that needed to be developed. As a result, there was a great demand for staff. As social work in Ukraine also emerged in 1991, it was impossible to provide social services with qualified staff - universities have only just begun training such professionals. Therefore, the idea arose to create a nationwide public organization that would be training social workers in local communities to involve volunteers in the implementation of social projects. The All-Ukrainian Public Center "Volunteer" became such an organization (All-Ukrainian Public Center "Volunteer", 2020). Continuing the tradition, this public organization is still actively implementing programs to train coordinators of volunteer activities throughout Ukraine.

The All-Ukrainian Community Center "Volunteer" pays special attention to the communities of Donetsk and Luhansk regions, which found themselves in difficult life circumstances. Particular attention Ukrainian Community Center "Volunteer" gives communities Donetsk and Lugansk regions, in difficult circumstances, located on the territories controlled by Ukraine along the line of hostilities. 
Currently the project "Training of managers of volunteer programs for a systematic professional approach in working with volunteers in Eastern Ukraine" implemented in the period from April 2020 to April 2021 with the support of the United Nations Recovery and Peacebuilding Programme (AllUkrainian Public Center "Volunteer", 2020). The project is implemented by four UN agencies: The United Nations Development Programme, the UN Entity for Gender Equality and the Empowerment of Women, the United Nations Population Fund, and the Food and Agriculture Organization of the United Nations. The experts of the All-Ukrainian Community Center "Volunteer" provided training for professional state agencies and NGOs helping them to develop youth volunteer programs within the framework of the project. Currently, these volunteer programs are implemented in communities in Eastern Ukraine, with the active participation of young people.

The implementation phase of these youth volunteer programs occurred during the COVID-19 pandemic and related quarantine restrictions in Ukraine. This caused organizational and methodological problems for their coordinators, negatively affecting the activity of young people in volunteer programs, their social initiative, and motivation to develop their volunteer initiatives ("On the establishment of quarantine to prevent the spread of acute respiratory disease COVID-19, COVID-19 coronavirus SARS-CoV-2", 2020; "On prevention of the spread of COVID-19 acute respiratory disease caused by the SARS-CoV-2 coronavirus in Ukraine", 2020).

The analysis of such experience is valuable and provides key insights to identify the effective organization of volunteers' activities in the conditions of the quarantine restrictive measures in the territories adjacent to the zone of combat.

\section{Literature Review}

The COVID-19 pandemic has suddenly changed the personal and professional lives of billions of citizens and forced governments around the world to adapt quickly to the new reality which is characterized by increasing mortality, social distancing, and remote working (Oldekop et al., 2020).

Countries around the world face enormous challenges in the fight against the virus, making progress for sustainable development and finding new ways to achieve results in the conditions caused by pandemic COVID-19. They are forced to make major changes in social policy, to mobilize human resources to support vulnerable communities and individuals in difficult life circumstances (Barbier \& Burgess, 2020; Naidoo \& Fisher, 2020).

Researcher G. Goodwin (Goodwin, 2019), N. Kapucu (Kapucu, 2006), E. Ostrom (Ostrom, 1996) have pointed out that the government's response 
during the crisis should be coordinated and supported by other actors (citizens, civil society, public and non-governmental organizations, and other). Volunteering plays an important role in this context because they participate in the volunteer programs implemented by state and public organizations; and provide appropriate social services to members of their communities without financial reward (Nabatchi et al., 2017). Working with volunteers and volunteer groups of community organizations to provide social services can fill gaps and prevent overloading of state institutions during crisis, such as COVID-19.

Researchers V. Gazley and J. Brudney (Gazley \& Brudney, 2005) analyzed the crisis and the role of volunteers in local communities, and concluded that the main obstacle to such volunteering may be the inability of state and public organizations to effectively organize volunteer activities in a crisis.

Sharing the opinion of researchers, we consider it necessary to investigate the organizational and methodological problems faced by state and public organizations implementing volunteer programs in eastern Ukraine, under the quarantine restrictions caused by the COVID-19 pandemic.

\section{Methodology}

The study was conducted in December 2020 using the rapid appraisal methodology for rapid collection of information and qualitative understanding of the situation, making the necessary management decisions within the project or program (Beebe, 1995). To achieve the tasks of "rapid appraisal", the authors chose the focus group method.

The focus group method is a group interview conducted by a moderator according to a pre-designed scenario with a small group of representatives of the surveyed contingent of respondents, similar in basic social characteristics. Our focus group was conducted according to the methodology developed by American sociologists (Merton \& Kendall, 1946).

Twenty-two coordinators of youth volunteer programs of state and public organizations of Donetsk and Luhansk regions of Ukraine were involved in focus groups. They implement the author's volunteer programs developed within the project of the All-Ukrainian Public Center "Volunteer" - "Training of volunteer program managers for a systematic professional approach to working with volunteers in Eastern Ukraine ".

This project is being implemented in the period from April 2020 to April 2021 with the support of the UN Peacebuilding Programme and supported by four UN agencies: the United Nations Development Programme (UNDP), the UN Entity for Gender Equality and the Empowerment of Women (UN Women), the United Nations Population Fund (UNFPA), and the Food and Agriculture Organization of the United Nations (FAO). 
SOCIETY. INTEGRATION. EDUCATION

Proceedings of the International Scientific Conference. Volume III, May $28^{\text {th }}-29^{\text {th }}$, 2021. 316-326

Thus, a total of 22 respondents took part in the survey (Table 1). The authors were limited in their ability to meet respondents in the offline mode due to quarantine restrictions caused by the COVID-19 epidemic. Therefore, the focus groups were held online in Zoom. Each focus group (2 groups of 11 respondents each) worked in a separate virtual office.

Table 1 Information about Respondents

\begin{tabular}{|c|c|c|}
\hline & Focus group 1 & Focus group 2 \\
\hline Total & 11 & 11 \\
\hline \multirow{5}{*}{ Age range } & $18-25-1(4.55 \%)$ & $18-25-0$ \\
\hline & $26-35-5(22.73 \%)$ & $26-35-6(27.27 \%)$ \\
\hline & $36-45-4(18.18 \%)$ & $36-45-4(18.18 \%)$ \\
\hline & $46-55-1(4.55 \%)$ & $46-55-1(4.55 \%)$ \\
\hline & 55 and older -0 & 55 and older -0 \\
\hline \multirow[t]{3}{*}{ Experience (\%) } & $1-5$ years $-8(36.36 \%)$ & $1-5$ years $-9(40.91 \%)$ \\
\hline & $6-10$ years $-1(4.55 \%)$ & $6-10$ years $-1(4.55 \%)$ \\
\hline & More than 11 years - $2(9.09 \%)$ & More than 11 years $-1(4.55 \%)$ \\
\hline \multirow[t]{6}{*}{ Position (\%) } & Volunteer specialist - 2 (9.09\%) & Volunteer specialist - 5 (22.73\%) \\
\hline & Head of Department - 3 (13.64\%) & Head of Department - 1 (4.55\%) \\
\hline & Project coordinator - $4(18.18 \%)$ & Project coordinator - $3(13.64 \%)$ \\
\hline & Instructor - 1 (4.55\%) & Instructor - 1 (4.55\%) \\
\hline & Social pedagogue - $1(4.55 \%)$ & Social pedagogue -0 \\
\hline & Practical psychologist -0 & Psychologist - 1 (4.55\%) \\
\hline $\begin{array}{l}\text { Education, } \\
\text { scientific degree } \\
(\%)\end{array}$ & High education - $11(100 \%)$ & High education - 11 (100\%) \\
\hline $\begin{array}{l}\text { Represented } \\
\text { institution (\%) }\end{array}$ & $\begin{array}{l}\text { Government organizations }-4 \\
(18.18 \%) \\
\text { NGOs }-7(31.82 \%)\end{array}$ & $\begin{array}{l}\text { Government organizations - } 5 \\
(22.73 \%) \\
\text { NGOs }-6(27.27 \%)\end{array}$ \\
\hline
\end{tabular}

$n=22$

The purpose of the study was to analyze the problems faced by coordinators of the youth volunteer programs of state and public organizations of Donetsk and Luhansk regions of Ukraine due to the COVID-19 epidemic and the quarantine restrictions.

The list of questions for the focus groups included:

1) the problems faced by the coordinators of youth volunteer programs in the conditions of restrictive quarantine measures caused by the COVID-19 pandemic;

2) ways and means of overcoming the problems faced by the coordinators of youth volunteer programs in the conditions of restrictive quarantine measures caused by the COVID-19 pandemic; 
3) resources used to address the challenges faced by coordinators of the youth volunteer program in the context of restrictive quarantine measures caused by the COVID-19 pandemic;

4) the needs to be met for the effective implementation of youth volunteer programs in the context of restrictive quarantine measures caused by the COVID-19 pandemic;

5) positive aspects of the experience gained during the restrictive quarantine measures caused by the COVID-19 pandemic.

The results of the focus groups were word for word transcribed and translated into English. To identify the descriptive topics, the pre-coding was done, and later clarified and interpreted using the MaxQDA10 program.

\section{Research Results}

The analysis of the answers to the focus groups questions provided the basis for authors to found out the problems faced by the coordinators of youth volunteer programs in the conditions of restrictive quarantine measures caused by the COVID-19 pandemic.

Survey results showed that the most common problems (63\%): organization of online training and lack of motivation of volunteers to work in this format; the inaccessibility of the initial results due to obstacles in the form of lockdowns, the inability to gather volunteers during supervision and to control activities in the process; providing volunteers with specific resources by restricting their import to the region; ban on mass gathering; the majority of volunteer programs participants who received volunteer assistance are at risk of infection with COVID-19 (81\%). The distance learning of student volunteers led to the transfer of the planned activities into online format, that has not produced the desired results due to lack of live communication, limited opportunities, decreasing of young people activity (50\%). The constant monitoring of compliance with quarantine restrictions; the impossibility of online training volunteers due to lack of necessary equipment and stable Internet; the online training has not given the desired results; prohibition of the Lead Donor to conduct offline activities in the period of stabilizing the pandemic situation (44\%); limited access to government agencies and officials. Another problem in the areas adjacent to the areas of hostilities was the cancellation of local elections from November 2020 to the present (25\%), which led to a slowdown in the implementation of certain tasks of volunteer programs.

The analysis of the results showed that in the context of restrictive quarantine measures caused by the COVID-19 pandemic, it is important to strengthen social ties for the effective implementation of volunteer programs; 
create a strong, secure, cohesive community; strengthen the public activity; provide assistance and services.

It should be taken into account that there are many issues faced by coordinators of the volunteer program in the context of restrictive quarantine measures caused by the COVID-19 pandemic, so it is important to understand ways and means to overcome the problems.

When asked: "How did you overcome the problems you mentioned above?" they answered:

"The number of online meetings was increased and opportunities were found to gather volunteer team leaders for an offline training session, and all participants of the regional volunteer project for the Volunteer Fest (Solodar city) in compliance with all sanitary and anti-epidemic measures";

"We diversified the process of learning online, using interactive methods of work";

"The problem with a ban on public events was solved with the help of the Zoom platform. In the initial submissions, there were many participants over 60 years of age with disabilities and musculoskeletal problems. They were unable to take part in the activities of the volunteer youth program due to health concerns, so it was decided to hold the event in rehabilitation centers and a+boarding school";

"Problems of access to officials were solved through negotiations and meetings";

"During the lockdown, volunteers carry out their activities according to an individual schedule accompanied by the leader of the volunteer group. The initiative is implemented online. This is usually a telephone mode which is accompanied by video communication. Taking into account the characteristics of the beneficiaries, volunteers began to conduct individual training on how to use various social networks. "

The responses received from the volunteer program coordinators showed that despite the difficulties they faced in the context of the restrictive quarantine measures caused by the COVID-19 pandemic, the implementation of youth volunteer programs was carried out by making adjustments to planning, coordination, and control. Young people were actively involved in volunteer programs, which allowed them to make a personal contribution to solving social problems, to explore their capabilities.

The analysis of responses showed that 16 respondents (72.73\%) indicated they were not quite ready to overcome the problems faced by the coordinators of volunteer programs in the context of restrictive quarantine measures caused by the COVID-19 pandemic, and 6 respondents (27.27\%) indicated the absolute readiness to overcome problems. It should be noted that the following problems were identified, which the coordinators of volunteer programs $(75 \%$ of 
respondents) were not ready to overcome: delays in purchasing the necessary materials/equipment due to lack of supplies for events by volunteers 16(72.73\%) people; unwillingness to spend time on establishing cooperation with the new bodies of the local council for the implementation of the youth volunteer program - 11(50\%) people; insufficient technical equipment of volunteers (lack of technical support during communication, lack of transport between cities that made it impossible to provide volunteer services) 10(45.45\%) people.

It is also undeniable that needs of the population in social care, psychological support and protection are growing. The coordinators of youth volunteer programs need to keep in mind the great responsibility they carry. After all, on the one hand, they are responsible for the volunteers themselves and their actions, and on the other - for those who receive voluntary assistance.

The responses prompted us to find out what resources were used to address the challenges faced by youth volunteer program coordinators in the context of the restrictive quarantine measures caused by the COVID-19 pandemic. The participants of one focus-group (11 people) have identified such resources: "The improvement of online tools of work, explanatory work on the observance of norms of behavior during the pandemic; oral agreements and negotiations with all participants involved in the project; conducting remote events, negotiations ".

The participants of the second focus group included "...the ability to communicate with people as an important resource in solving the problems they faced. As practice has shown, most volunteers learned about our project not from Internet sources, but through personal communication with the project manager and coach".

The importance of finding effective communication between youth volunteer program coordinators and young people when recruiting volunteers should not be underestimated. This will facilitate the participation of young people in various community volunteer projects.

Among the professional needs that should be met for the effective implementation of youth volunteer programs in the context of restrictive quarantine measures caused by the COVID-19 pandemic, respondents indicated: providing a stronger technical basis for online work, Zoom account for NGOs, and additional co-financing for activities to prevent the spread of infection - 11 (50\%) people; advanced training through online education, master classes on working with the Google platform; gaining coaching skills in various areas. Also, respondents indicated: deepening knowledge in the psychology of communication - 19 (86.36\%) people; planning of risks that may arise during the implementation of the program and options for overcoming those; flexibility of the program, the ability to make adjustments that do not affect the quality and 
effectiveness - 16 (72.73\%) people; developing guidelines for advocacy of volunteer programs - 20 (90.91\%) people.

The coordinators of the youth volunteer programs chose supervision as a special form of communication. The main task of the volunteer program coordinator is to conduct regular supervision of volunteers. A large group of community volunteers is students youth. Therefore, their theoretical and practical training for volunteering is important. Volunteer training should be clearly structured, have a theoretical and practical basis, based on confirmed areas of volunteer training.

The obtained results also showed positive outcomes due to the change in the usual format of development of youth volunteer programs, which have been noted by the respondents. Among those: mastering remote forms of communication by employees - 15(68.18\%) persons; development of qualitatively new content of training programs for volunteers - 12(54.55\%) people; opportunity to use the Internet for advertising volunteer programs - 9 (40.91\%) people; the emergence of online volunteering - 11(50\%) people. The identified positive changes provide a basis for optimistic forecasts for the implementation of youth volunteer programs in the context of restrictive quarantine measures caused by the COVID-19 pandemic.

\section{Conclusions and Recommendations}

The social changes caused by the COVID-19 pandemic have affected the development and implementation of youth volunteer programs in communities adjacent to the Joint Forces Operation Area in Eastern Ukraine.

To summarize the results of conducted focus groups the rapid appraisal methodology was used. This methodology provides developing a preliminary, qualitative understanding of a situation, identifying the most acute problems and available means to solve them, and provide the basis to identify problems caused by quarantine restrictive measures.

The authors grouped the results into two categories:

1. Organizational - organization of online training: often the inability to train volunteers online due to lack of necessary equipment and Internet; lack of motivation for participants to work in this format; providing specific resources needed for volunteer work by limiting their visits to the region during the lockdown period; ban on holding mass events, difficulties in gathering volunteers and participants in one room, weakening of youth activity due to lack of live communication; constant monitoring of quarantine restrictions; limited access to government agencies and officials; insufficient technical equipment of volunteers (lack of technical support for communication, lack of transport between cities, which made it impossible for residents of cities and towns to 
receive medicines and other assistance). A separate problem in the territories neighboring to the areas of hostilities was the cancellation of local elections in united territorial communities and the power vacuum of local governments (from November 2020 to the present).

2. Methodological - difficulties in motivating young people to participate in long-term volunteer programs, the offline format orientation of volunteer training programs and lack of experience in the online volunteer training; lack of experience in online recruiting volunteers, difficulties in providing a platform for informal communication of volunteers; lack of opportunity for intervision and supervision of volunteer activities, and other.

According to the respondents, the reduction in the number of youth activities due to quarantine restrictions does not mean that young people should stop, but rather the opposite. It is necessary to transfer civic activism to an online format temporarily, where the opportunity to participate in volunteer programs in communities can become more accessible for young people. Quarantine is a time to master the knowledge on implementation of social projects in order to "shoot" offline at the first opportunity with more strength and motivation.

The main provisions and conclusions of the study were discussed and received a positive assessment at the meeting of the Department of Social Pedagogy and Social Work of the Institute of Human Sciences of Borys Grinchenko Kyiv University.

\section{Acknowledgements}

The study was conducted in the framework of the scientific theme of the Institute of Human Sciences of Borys Grinchenko Kyiv University "Personality in conditions of social transformations of modern Ukraine", registration number: 0116U002960, deadline - 5.2016-5.2021.

\section{References}

Barbier, E.B., \& Burgess, J.C. (2020). Sustainability and development after COVID-19. World Development, 135, 105082. Retrieved from https://doi.org/10.1016/ j.worlddev.2020.105082

Beebe, J. (1995). Basic Concepts and Techniques of Rapid Appraisal. Human Organization, 54(1), 42-51.

Declaration on General Principles of State Youth Policy in Ukraine. (1993). Vidomosti Verkhovnoyi Rady Ukrayiny, (16). Retrieved from https://zakon.rada.gov.ua/ laws/show/2859-12\#Text

Gazley, B., \& Brudney, J.L. (2005). Volunteer involvement in local government after September 11: The continuing question of capacity. Public Administration Review, 65(2), 131-142. 
Goodwin, G. (2019). The problem and promise of coproduction: Politics, history, and autonomy. World Development, 122, 501-513.

Kapucu, N. (2006). Interagency communication networks during emergencies: Boundary spanners in multiagency coordination. The American Review of Public Administration, 36(2), 207-225.

Merton, R.K., Kendall, P.L. (1946). The Focused Interview. The American Journal of Sociology, 51(6), 541-557.

Naidoo, R., \& Fisher, B. (2020). Reset Sustainable Development Goals for a pandemic world. Nature, 583(7815), 198-201. https://doi.org/10.1038/d41586-020-01999-X

Nabatchi, T., Sancino, A., \& Sicilia, M. (2017). Varieties of participation in public services: The who, when, and what of coproduction. Public Administration Review, 77(5), 766-776.

Oldekop, J.A., Horner, R., Hulme, D., Adhikari, R., Agarwal, B., Alford, M., Bakewell, O., Banks, N., Barrientos, S., Bastia, T., Bebbington, A.J., Das, U., Dimova, R., Duncombe, R., Enns, C., Fielding, D., Foster, C., Foster, T., Frederiksen, T., Gao, P., ... Zhang, Y. F. (2020). COVID-19 and the case for global development. World development, 134, 105044. https://doi.org/10.1016/j.worlddev.2020.105044

Ostrom, E. (1996). Crossing the great divide: coproduction, synergy, and development. World development, 24(6), 1073-1087.

All-Ukrainian Public Center "Volunteer". (2020). History of this center. Retrieved from http://volunteer.kiev.ua/

On the establishment of quarantine to prevent the spread of acute respiratory disease COVID-19, COVID-19 coronavirus SARS-CoV-2, Resolution of the Cabinet of Ministers of Ukraine No. 392. (2020). Ukraine. Retrieved from https://zakon.rada.gov. ua/laws/show/392-2020-п?lang=uk\#Text

On prevention of the spread of COVID-19 acute respiratory disease caused by the SARSCoV-2 coronavirus in Ukraine, Resolution of the Cabinet of Ministers of Ukraine No. 211. (2020). Ukraine. Retrieved from https://zakon.rada.gov.ua/laws/show/2112020-п\#Text 